\title{
O MULTILINGUISMO E AS NOVAS TECNOLOGIAS DAS LÍNGUAS NO SÉCULO XXI
}

\section{MULTILINGUALISM AND THE NEW LANGUAGE TECHNOLOGIES IN THE XXI CENTURY}

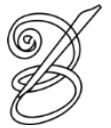 \\ Francisco Cláudio Sampaio de Menezes ${ }^{1}$ \\ Professor do curso de Línguas Estrangeiras Aplicadas da Universidade de Brasília \\ Doutorando em Ciência da Informação (UnB) \\ (LEA - UnB - Brasília - Brasil) \\ claudiomenezes@unb.br
}

\begin{abstract}
Resumo: $\mathrm{O}$ artigo aborda o conceito de vitalidade linguística e seus atributos, as novas tecnologias de tratamento da língua e algumas questões relativas à situação da língua portuguesa no tocante aos indicadores de vitalidade linguística. A partir dessa análise, o autor elabora algumas reflexões e formula propostas para ampliar a vitalidade linguística do português no mundo digital.

Palavras-chave: Vitalidade linguística, multilinguismo no ciberespaço, tecnologias da língua, indicadores
\end{abstract}

Abstract: The article presents the concept of linguistic vitality and its attributes, the new language technologies. Also, it raises some questions on the situation of Portuguese as regards to linguistic vitality indicators. From this analysis, the author elaborates some reflections and formulates some proposals to enlarge Portuguese linguistic vitality in the digital world.

Keywords: Linguistic vitality, multilingualism in cyberspace, language technologies, indicators

\section{Introdução}

$1 \begin{aligned} & \text { uitos temos ciência da necessidade de manter e eventualmente ampliar o uso da } \\ & \text { língua portuguesa na sociedade. Colocada a questão dessa forma, estaríamos } \\ & \text { diante de uma afirmação tautológica que Nelson Rodrigues denominaria de }\end{aligned}$ óbvio ululante, visto que esse anseio por assegurar a vitalidade de cada língua é comum a todos os seus falantes. No entanto, cabe-nos refletir um pouco sobre o contexto em que precisamos buscar esse protagonismo para a língua que falamos, particularmente em relação às línguas de maior presença mundial num ambiente tecnológico que muda com velocidade espantosa. O presente artigo analisa a questão da vitalidade da língua portuguesa no mundo digital e apresenta algumas recomendações para ampliá-la. Está constituído dos seguintes tópicos: 1. Introdução; 2. Vitalidade Linguística no Mundo Digital; 3. Multilinguismo e 
Tecnologias; 4. A Língua Portuguesa no Mundo Digital; e 5. Reflexões e Considerações Finais.

\section{Vitalidade Linguística no Mundo Digital}

A presença das línguas no mundo digital passou a preocupar autoridades e especialistas por se tratar de uma questão importante para a preservação e garantia do uso de cada língua nos dias de hoje. Por esse motivo, estudos têm mostrado a necessidade de políticas e estratégias para assegurar a inclusão e manutenção das línguas no ciberespaço. Desse modo, algumas novas metodologias e tecnologias têm sido elaboradas tanto para a inclusão de novas línguas no mundo digital, como também para ampliar o uso de uma língua já presente no ciberespaço. Trata-se, portanto, de assegurar presença no mundo digital às línguas dele ausentes e assegurar, e eventualmente ampliar, o uso das línguas já incluídas no ciberespaço, como é o caso da língua portuguesa.

Convêm, a esse respeito, elaborar um pouco o conceito de vitalidade linguística, como apresentado em alguns documentos da UNESCO (2013) para evidenciar a situação das

86 línguas nesse aspecto. De acordo com um desses estudos, a vitalidade linguística não pode ser atribuída a um fator isolado. As comunidades linguísticas são diversas e têm suas próprias especificidades, além das dificuldades de obter estatísticas confiáveis e sistemáticas sobre essa situação. De qualquer modo, no encontro de especialistas da UNESCO (2013) que produziu o citado estudo, foram aceitos nove fatores para caracterizar a vitalidade linguística, as atitudes e a urgência de criação de documentação.

São eles:

1. Vitalidade Linguística: 1) Transmissão da Língua entre Gerações; 2) Número absoluto de falantes; 3) Proporção de Falantes na População Total; 4) Mudanças nos Domínios de Uso da Língua; 5) Participação da Língua em Novos Domínios e na Mídia; 6) Disponibilidade de Materiais para Educação e Alfabetização.

2. Atitudes e Políticas linguísticas: 1) Atitudes e Políticas Governamentais e das Instituições no tocante à língua (incluindo seu uso e status oficial); 2) Atitudes da Comunidade de Falantes em relação a sua própria língua.

3. Urgência da Necessidade de Documentação: 1) Tipo e Qualidade da Documentação. 
Cada um dos fatores acima pode ser explorado em detalhe, visando a conhecer a situação de uma língua e, em particular, do português, no sentido de orientar ações pertinentes.

Abordaremos em seguida a questão principal deste artigo: as novas tecnologias das línguas no século XXI. Seu uso, naturalmente, depende da disponibilidade prévia da língua no ambiente tecnológico digital, ou seja, que recursos para uso da língua já tenham sido desenvolvidos e disponibilizados no ciberespaço. Vale dizer, antes de usar as tecnologias particularmente e predominantemente tecnologias digitais - é requisito para tal que as etapas para a sua inclusão digital já tenham sido cumpridas, como é o caso do português, embora em grau ainda insatisfatório como veremos mais adiante.

Assim, tanto para compreender o processo como para focar nas etapas mais relevantes, as etapas para inclusão de uma língua no ciberespaço, ou seja:

a) Desenvolvimento de Recursos Linguísticos;

b) Desenvolvimento de Recursos de Tecnologia da Informação;

c) Desenvolvimento de Conteúdo Cultural; e

d) Desenvolvimento de uma Comunidade de Usuários (em nível local, nacional e internacional).

Ao conhecer tais etapas, torna-se possível concentrar esforços, recursos e políticas naquela etapa em que a língua estiver menos atendida visto que o processo de vitalidade linguística tanto envolve tecnologia como mobilização pessoal e institucional dos principais atores.

\section{Multilinguismo e Tecnologias}

Como sabemos, o português é língua oficial de Angola, Brasil, Cabo Verde, GuinéBissau, Macau, Moçambique, Portugal, São Tomé e Príncipe, Timor-Leste e, mais recentemente, da Guiné Equatorial. É a terceira língua europeia mais falada no mundo, com 220 milhões de falantes. Há também registro de núcleos de falantes do português em outros países, como é o caso do Luxemburgo, Andorra, França, Alemanha, Reino Unido, Suíça e Bélgica. Além disso, o português é língua oficial de organizações internacionais, tais como a União Europeia, o Mercosul, a União Africana e obviamente a CPLP. Por sua importância estratégica, torna-se, portanto, imperativo formular políticas e desenvolver ações para 
assegurar a vitalidade linguística do português, particularmente no ambiente tecnológico atual. Daí a necessidade de uma prática de política linguística que contemple a tecnologia da linguagem para o português, algo ainda muito incipiente no espaço lusófono.

\section{3.a) Tratamento das Línguas em Computador}

As tecnologias da linguagem são abordadas através do Processamento da Linguagem Natural (PLN), do qual a linguística computacional é um componente importante. Trata-se de uma área que envolve conhecimento interdisciplinar, principalmente da linguística, da ciência da computação, de ciências cognitivas e também da semiótica.

O quadro abaixo mostra de forma sintética a evolução do PLN desde seus primórdios:

Evolução dos Sistemas de PLN

\section{Década de 50: A Tradução automática}

Sistematização computacional das classes de palavras da gramática tradicional

Identificação computacional de poucos tipos de constituintes oracionais

Década de 60: Novas aplicações e criação de formalismos

Primeiros tratamentos computacionais das gramáticas livres de contexto

Criação dos primeiros analisadores sintáticos

Primeiras formalizações do significado em termos de redes semânticas

Década de 70: Consolidação dos estudos do PLN

Implementação de parcelas das primeiras gramáticas e analisadores sintáticos

Busca de formalização de fatores pragmáticos e discursivos 


\section{Década de 80: Sofisticação dos sistemas}

Desenvolvimento de teorias linguísticas motivadas pelos estudos do PLN

\section{Década de 90: Sistemas baseados em "representações do conhecimento”}

Desenvolvimento de projetos de sistemas de PLN complexos que buscam a integração dos vários tipos de conhecimentos linguísticos e extralinguísticos e das estratégias de inferência envolvidos nos processos de produção, manipulação e interpretação de objetos linguísticos

Fonte: Dias da Silva et al., Introdução ao Processamento das Línguas Naturais e Algumas Aplicações, Série de Relatórios do Núcleo Interinstitucional de Linguística Computacional NILC - ICMC-USP, Caixa Postal 668, 13560-970 São Carlos, SP, Brasil

De acordo com o linguista Marcel Diki-Kidiri (2007), o desenvolvimento de recursos de tecnologia da informação constitui elemento primordial para assegurar a vitalidade de uma língua no ciberespaço.

Nesse sentido, recentes publicações fazem um apanhado bastante completo sobre o assunto. O capítulo “Tecnologia da Linguagem para o Português”, do Livro Branco da Língua Portuguesa elaborado por Branco (2012), que comentaremos a seguir, é uma dessas publicações sobre o tema.

Em primeiro lugar, realçamos que as tecnologias da linguagem se fazem presentes em um contexto em que diversas tecnologias se interceptam: tecnologia do processamento de texto, tecnologia da fala, tecnologias multimídia e multimodais, tecnologias da linguagem e tecnologias do conhecimento.

Editado pela rede acadêmica META-NET, da União Europeia, o Livro Branco apresenta os elementos essenciais para o uso das tecnologias da linguagem para o português:

1. Arquitetura das Aplicações;

2. Áreas Centrais de Aplicação;

3. Outras Áreas de Aplicação; e

4. Formação acadêmica 
A arquitetura das aplicações se estrutura geralmente em 3 módulos:

a) Pré-processamento: limpeza de dados, análise ou remoção de formatação e detecção do idioma;

b) Análise gramatical: detecção do verbo e dos seus complementos e modificadores, detecção de elementos de outras categorias, identificação da estrutura das frases;

c) Análise semântica: desambiguação, resolução de anáforas e representação do significado da frase num modelo interpretável pela máquina.

O citado estudo da União Europeia apresenta um inventário de diversas aplicações das tecnologias da linguagem para o Português, a saber:

a) Verificação da linguagem;

b) Busca na Web;

c) Interação por Fala;

d) Tradução Auxiliada por Computador ou Tradução Automática;

Cabe também incluir ainda a Sumarização Automática como uma aplicação relevante para a vitalidade linguística.

Além dessas aplicações, na atividade acadêmica, sobretudo em Portugal e no Brasil têm sido desenvolvidos diversos sistemas de processamento de língua natural, tais como: manipulação de bases de dados, sistemas tutores, sistemas de automação de tarefas administrativas, programação automática, sistemas de processamento de texto científico, sistemas especializados, sistemas acadêmicos,

\section{a) Verificação da linguagem}

Programas de verificação de linguagem, em geral aplicam regras conhecidas aos textos. É o caso dos corretores ortográficos, de gramática ou de estilo embutidos na maioria dos processadores de texto.

Usuários de programas de edição de texto, como é o caso do MS Word e do BR Office estão habituados a utilizar ferramentas de correção ortográfica. Esses processadores de texto, em geral, por se tratarem de programas que não oferecem uma revisão gramatical acurada, 
não oferecem a funcionalidade de correção gramatical. Há, no entanto, a oferta de diversas ferramentas de correção ortográfica do Português, como é o caso do FLIP. Como corretor gramatical, podemos citar o CoGoOO. Temos ainda alguns programas de conversão do português ao acordo ortográfico firmado entre os países de língua portuguesa. É o caso do BRACorpus, de autoria do Prof. Marcos de Campos Carneiro, da UnB (2014).

A correção gramatical do português já conta com um software desenvolvido em colaboração da Universidade de Campinas (UNICAMP), com o Núcleo Interinstitucional de Linguística Computacional (NILC). Trata-se do ReGra (Revisor Gramatical), integrado ao MS Word e ao processador de texto REDATOR ${ }^{2}$.

\section{b) Busca na Web}

A geração atual de buscadores, em intranets ou em bibliotecas digitais talvez seja a tecnologia de linguagem de maior uso. No entanto, para uma busca de informação mais elaborada há necessidade de integrar conhecimentos linguísticos pouco utilizados nas arquiteturas de informação atuais.

Algumas iniciativas em escala laboratorial já permitem a recuperação de informações com recurso a thesauri e bases de dados ontológicas. Alguns dos recursos já desenvolvidos para esse fim são a ontologia lexical WordNet.PT e WordNet.BR.

A expectativa no tocante à busca na Web será uma associação desses recursos aos conceitos da Web Semântica, ainda em fase incipiente de implementação prática.

A hegemonia do Google no momento é preocupante, visto que na prática algumas iniciativas de motores de busca específicos para a língua portuguesa não conseguiram se consolidar. É o caso do AEIOU, em 1996 e do Sapo, em 1997 em Portugal e o Achei ou o Giga Busca, no Brasil.

\section{c) Interação por Fala}

A tecnologia da fala é a base para se criar interfaces que permitam ao usuário interagir com máquinas, por meio da voz em substituição ao "mouse”. Essa tecnologia se apoia em três dimensões principais:

i. o reconhecimento automático da fala seleciona as palavras que foram pronunciadas em sequência pelo usuário; 
ii. $\quad$ A gestão do diálogo indica a ação a ser efetivada a partir da entrada vocal emitida pelo usuário e pela funcionalidade do sistema de interação por fala;

iii. $\quad$ A síntese de voz (texto - para - fala) transforma a saída do sistema em sons para o usuário.

Conforme mencionado no Livro Branco sobre “A Língua Portuguesa na Era Digital”, os sistemas de reconhecimento de voz do português europeu e do português do Brasil tem apresentado bom desempenho.

O estado da arte da síntese de fala para o português (“output” vocal emitido pelo computador) é similar ao do reconhecimento de fala, apresentando desempenho satisfatório.

E, por essa razão, empresas estão atuando com sucesso nesse mercado. É o caso das empresas Nuance (EUA) e Loquendo (Itália), a SVOX e a Voice Interaction (Portugal). No mercado brasileiro, destaca-se a empresa VOCALISE, que oferece produtos e serviços de texto-para-fala, fala-para-texto, reconhecimento automático de fala, busca em fala gravada, etc.

Quanto à gestão de diálogo, a DigA - de domínio público - é a única aplicação completa para o português europeu. Tem-se notícia também da aplicação Olympus SDS, de código aberto, mas insuficientemente testada quando da publicação do Livro Branco citado.

\section{d) Tradução Auxiliada por Computador (TAC) ou Tradução Automática} (TA)

A tradução auxiliada por computador é um campo de pesquisa de aplicações que tem sido objeto de estudo desde 1946. A primeira experiência de TA real, do russo para o inglês, foi realizada em 1954, na Universidade de Georgetown, com um vocabulário reduzido (250 palavras), textos cuidadosamente selecionados e seis regras de sintaxe. Essa experiência foi considerada satisfatória. Outro importante marco desse processo foram os estudos de Noam Chomsky sobre os conceitos de gramáticas formais, a partir de 1957. A União Europeia e países como África do Sul (11 línguas oficiais) e Índia (22 línguas oficiais) têm realizado programas de pesquisa nessa área. Iniciativas como a "Universal Networking Language” $(\mathrm{UNL})^{3}$ também são relevantes no campo da tradução automática.

A partir dos anos 80 houve uma grande retomada dos trabalhos de pesquisa e aplicações da TA. Resultante desse novo impulso, surgiram sistemas de tradução comercial, tais como o Systran. O Eurotra, um sistema europeu em constante desenvolvimento, também 
se iniciou nessa época. ${ }^{4}$

Entre os sistemas de TA que funcionam como auxiliares do tradutor humano cabe mencionar: o Trados Workbench (http://www.trados.com/), o IBM Translation Manager (http://www-4.ibm.com/software/ad/translat/) e o Déjavu (http://www.atril.com). Há, ainda, sistemas que efetuam uma pré-edição do documento original, de forma a criar uma versão em linguagem mais simples, como a usada pela Xerox no Systran ${ }^{5}$ (http://www.systransoft.com) para traduzir seus manuais técnicos em várias línguas.

No entanto, apesar dos avanços recentes, restam ainda diversos problemas a serem resolvidos no campo da TA, como constatam diversos autores. Na citada publicação do NILC, considera-se que “... restam importantes questões de cunho linguístico a resolver (semântico e pragmático-discursivo, principalmente), tais como ambiguidades, referências anafóricas, etc. Como consequência, o desenvolvimento de sistemas completamente automatizados, que consideram questões linguísticas e extralinguísticas de forma profunda, principalmente em domínios abertos ou línguas naturais irrestritas, após mais de 50 anos de pesquisa, ainda é um desafio para a área de TA.”

\section{e) Sumarização Automática}

A sumarização sempre acompanhou a humanidade, desde a criação da imprensa. No entanto, na sociedade atual a necessidade de economizar tempo tem tornado a sumarização uma atividade mais premente, daí o surgimento da sumarização automática (sem contar a frequente sumarização de palavras, como ocorre nas comunicações por computador, particularmente, nas redes sociais).

O indiscutível crescimento do volume de dados digitais na sociedade da informação já alcançou números que superam a casa dos petabytes (1015 bytes) e exabytes (1018 bytes) tornando difícil processá-los com o uso de ferramentas ou aplicações de processamento de dados tradicionais. Vive-se numa sociedade na qual há necessidade de localizar e processar informação da forma mais rápida possível e é nesse contexto que surgiram as técnicas de sumarização automática de textos, cujo início data da década de 1950 com os trabalhos de Luhn, na empresa IBM.

Uma conceituação bastante simples de sumário formulada por Hovy[1] diz que um sumário é texto produzido a partir de um ou mais texto(s) cujo tamanho não pode ser superior à metade do tamanho do original. O conceito de texto inclui documentos multimídia, documentos on-line, hipertextos, etc. Diversos tipos de sumário são considerados na 
literatura: Indicativo, Informativo (Crítico), Extratos e Abstracts. Vale mencionar também que a sumarização está associada ao gênero Manchetes (headlines), Breve descrição (outlines), Minutas (minutes), Biografias (biographies), Abreviações (abridgments), Resumo de Filmes (movie summaries), Cronologias (chronologies), entre outros. Há diversas outras considerações sobre os tipos de sumário que não abordaremos agora, mas sublinho que na UnB estamos explorando a viabilidade de sumarizar dissertações de mestrado, como etapa inicial de uma metodologia para sua difusão entre estrangeiros. De acordo com a literatura da área, sumários podem ser classificados como informativos, indicativos ou críticos. As abordagens de sumarização, usualmente consideradas em função da quantidade e do nível de conhecimento linguístico que utilizam, são denominadas abordagem superficial e abordagem profunda (em alguns casos pode haver mesclagem de técnicas dando origem a uma abordagem híbrida).

No entanto, a elaboração automatizada de sumários com a mesma qualidade de sumários elaborados por entes humanos depende de diversos fatores tais como comprimento e gênero do texto fonte, estilo de escrita e uso do léxico. A literatura sobre o assunto traz 94 diversos critérios para a escolha das sentenças que irão figurar no SA, tais como abordagens linguísticas, estatísticas e centradas na informação ou combinação de ambas. O sumário automático consiste na seleção de excertos do original portadores da maior ostensividade comunicacional, garantindo dessa forma uma compreensão satisfatória do usuário.

A técnica mais usual de montagem de sumários automáticos é a "sumarização por extração por varredura do texto” usando técnicas de criação de sumários mediante a seleção de excertos do documento original. No caso da sumarização humana, se requer a habilidade de entender, interpretar criar um "abstract” e gerar um novo documento. Na SA, o procedimento é diferente: trata-se de classificar as sentenças do original de acordo com a sua relevância (ou com a sua ostensividade comunicativa) ou probabilidade de compor o "melhor sumário”.

A sumarização automática em língua portuguesa tem recebido uma atenção especial de alguns grupos de pesquisa de universidades, principalmente em Portugal e no Brasil, como nas Universidades do Porto e de Lisboa, na UFSCar, na USP e na UFRGS, entre outras. Resultante desse trabalho, diversos sumarizadores de uso acadêmico estão em uso, como por exemplo, o GistSumm, o NeuralSumm, o DMLSumm, o UNLSumm e o iSummarize.

A avaliação da qualidade de sumários também tem sido objeto de pesquisa e resultado em algumas metodologias de construção de métricas, como é o caso dos sistemas ROUGE e 
BLEU, para o cálculo de precisão, revocação ou cobertura e medida-F.

\section{3.b) A Internet Multilíngue}

O desenvolvimento acelerado da Internet conduziu a um processo de desterritorialização da língua e criou novas necessidades tanto no plano tecnológico como no seu uso. Entre essas inúmeras aplicações da super-rede podemos citar: conexões em Banda Larga, dispositivos portáteis com acesso à Internet, acesso sem fio à Internet, dispositivos domésticos conectados, dispositivos multifuncionais, conteúdo web customizado (para portáteis), acesso à Internet ilimitado, cartões pré-pagos, comércio em eletrônico, M-comércio (E-comércio móvel), Redes Sociais e muitas outras aplicações.

Tal crescimento conduz a uma necessidade de estudos interlinguísticos que fazem uso de métodos similares em contextos similares envolvendo línguas diferentes. Considerando que as escolhas tecnológicas determinam com quem podemos conversar na Internet e que funcionalidades das tecnologias de comunicação mediada por computador podem condicionar o uso da língua, o conhecimento sobre quem está se comunicando e por meio de quais modos, quando e a que nível é um pré-requisito vital para o entendimento da CMC em uma escala mundial.

Considerando, por exemplo, o recente crescimento dos blogs, tecnologia que permite a publicação pessoal, como alcançar audiência de falantes de outras línguas? Como esse interesse em alcançar novas audiências pode afetar a escolha da língua de publicação nos blogs? Como assegurar a interoperabilidade das aplicações? Como alcançar a clientela de outros países por meio do comercio eletrônico? Essas são algumas questões que as pesquisas irão responder, partindo do pressuposto de que a Internet é um domínio multilíngue.

\section{A Língua Portuguesa no Mundo Digital}

Como já foi mencionado, o português ocupa a $5^{\mathrm{a}}$ posição em número de falantes no mundo. Quanto ao uso da nossa língua na Internet, os dados são controversos. No entanto, de acordo com a “Internet World Stats”, nossa língua também ocupava essa mesma posição em 31 de dezembro de 2013, com 121,8 milhões de usuários, superando línguas como o Japonês, o Alemão e o Francês. Não são conhecidos, todavia, dados estatísticos sobre como estão distribuídos esses usuários, particularmente quanto às tecnologias utilizadas. Seria importante aprofundar tais pesquisas, inclusive para identificar quais as aplicações e as tecnologias usadas no mundo lusófono. 


\section{Top Ten Languages in the Internet 2013 - in millions of users}

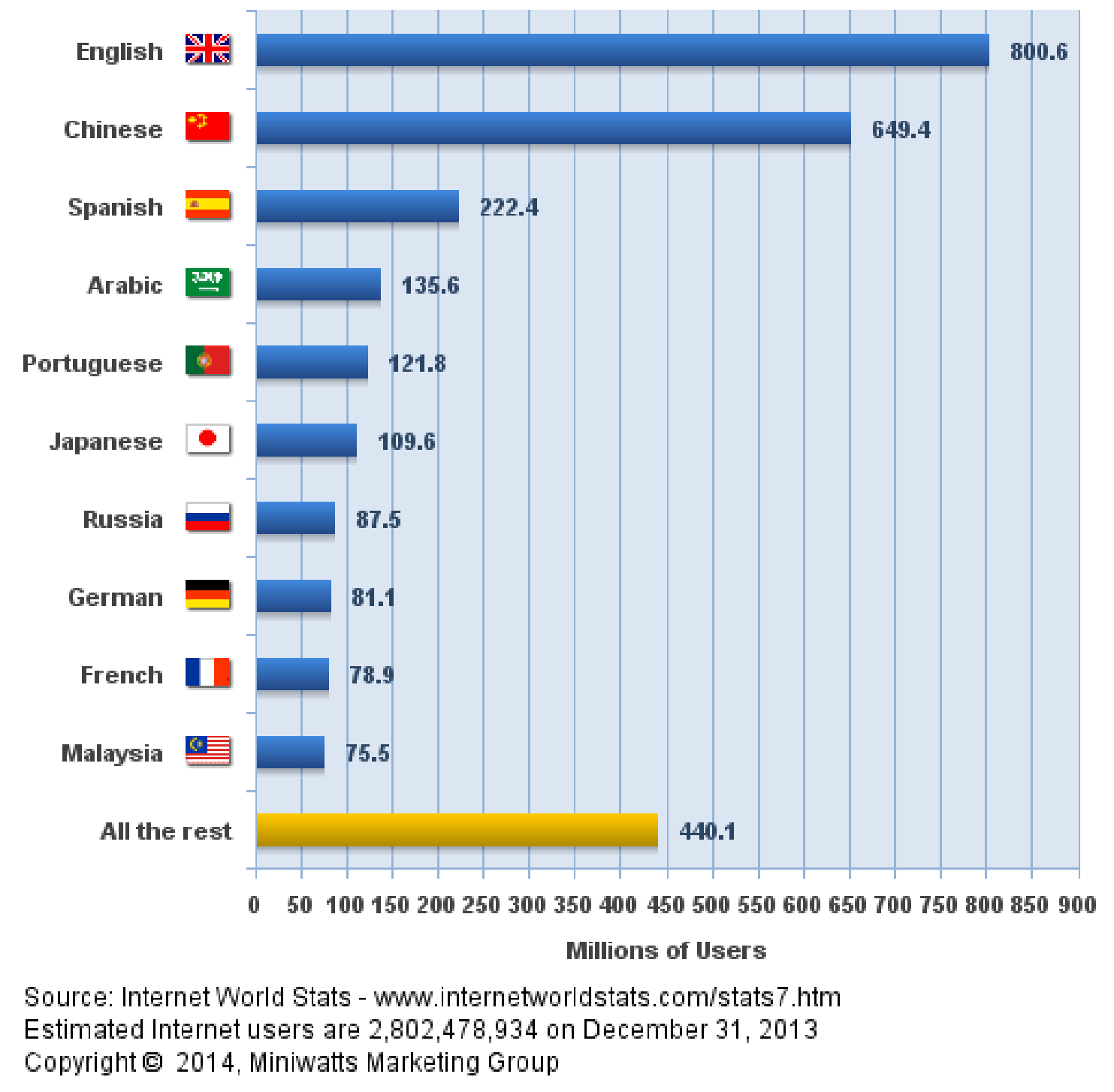

\section{Reflexões e Considerações Finais}

Como anteriormente mencionado, há nove fatores relevantes para caracterizar a vitalidade de uma língua. No nosso entender, alguns desses fatores estão bem atendidos pela situação atual da nossa língua, como é o caso da transmissão da língua entre gerações (fator 1), o número absoluto de falantes (fator 2), a proporção de falantes na população total (fator 3) e a disponibilidade de materiais para a educação e alfabetização (fator 6). Outros fatores, a nosso ver, necessitam de uma maior atenção e ação, como é o caso da mudança nos domínios no uso da língua (fator 4) e a participação do português em novos domínios e na mídia (fator 5). Quanto aos fatores atitudinais, as ações governamentais parecem despertar para uma maior 
ostensividade na ação política, em particular pela ação do Instituto Internacional da Língua Portuguesa, cobrindo de certa maneira os fatores da categoria 2. E, sem dúvida, há necessidade de uma maior operacionalidade nas questões de urgência da necessidade de documentação para melhoria do tipo e qualidade da documentação do português (fator 3.1).

Para tal, trazemos à consideração do leitor algumas breves ideias que poderão assegurar uma melhoria da vitalidade do português, particularmente no mundo digital:

a) intensificar pesquisas e estudos sobre a Web Semântica, com a participação das instituições acadêmicas dos países lusófonos e das instituições internacionais em que tomam parte;

b) promover pesquisas na área de linguística computacional e linguística de corpus com países com situação análoga a nossa em outros espaços linguísticos, como pode ser o caso da Rússia, Índia e África do Sul, que pertencem aos BRICS;

c) ampliar a pauta de apoio financeiro e institucional às pesquisas em PLN em português, tanto a nível nacional como internacional. A esse propósito, o novo Banco de Desenvolvimento criado na esfera dos BRICs poderá ter um papel decisivo neste particular.

d) Continuar a divulgação científica e a promoção de encontros temáticos sobre o uso da língua portuguesa no mundo digital.

e) Desenvolver um programa mais amplo para uso de ferramentas de PLN, através da criação de iniciativas empresariais nesse setor, a fim de disseminar produtos de uso das tecnologias da linguagem para o Português.

f) Ampliar a disponibilidade de ferramentas tais como as oferecidas pela Linguateca e pelo NILC para uso intensivo.

g) Ampliar o uso da língua portuguesa em organismos internacionais e participar em colegiados dos programas de cooperação de tais organismos. 


\section{REFERÊNCIAS BIBLIOGRÁFICAS}

BRANCO, António et al., A Língua Portuguesa na Era Digital, Spring Verlag Berlin Heidelberg, ISBN 978-3-642-29593-5, Disponível em http://www.meta-net.eu/whitepapers/ebook/portuguese.pdf, 2012, Acesso em: 5 de maio de 2015

CARNEIRO, M. D. C. (2014). Sistema BRACorpus. Certificado de registro de programa de computador. Processo: 14181-0. Titularidade: Fundação Universidade de Brasília. Instituto Nacional da Propriedade Industrial - INPI. Republica Federativa do Brasil. Ministério do Desenvolvimento, Indústria e Comércio Exterior, 2014.

DIKI-KIDIRI, Marcel, Como assegurar a presença de uma língua no ciberespaço, UNESCO, Disponível em http://portal.unesco.org/ci/en/files/24122/122027702017Cyberespace_PO.pdf/Cyberespace_P O.pdf, Traduzido do original "Comment assurer la présence d'une langue dans le cyberspace”, editado pela Divisão para a Sociedade da Informação, Setor para a Comunicação e Informação (Editor : Claudio Menezes) - Paris, UNESCO, 2007 : 80 p. ; 21 cm. (CI2007/WS/1), Acesso em: 5 de maio de 2015

UNESCO, “International Expert Meeting on UNESCO Programme Safeguarding of Endangered Languages" (Paris, 10-12 de março de 2013), Disponível em http://www.unesco.org/new/en/culture/themes/endangered-languages/dynamic-content-singleview-

98 meeting/news/expert_meeting_on_safeguarding_endangered_languages/\#.VTWUBLqUdF0, 2013, Acesso em: 5 de maio de 2015.

LANGUAGE VITALITY AND ENDANGERMENT, UNESCO Ad Hoc Expert Group on Endangered Languages, Documento adotado pelo "International Expert Meeting on UNESCO Programme Safeguarding of Endangered Languages” (Paris, 10-12 de março de 2013)

\footnotetext{
1 Currículo lattes Francisco Cláudio Sampaio de Menezes. Disponível em: http://lattes.cnpq.br/0356163607813759

2 Portal do Núcleo Interinstitucional de Linguística Computacional da Universidade de S. Paulo, Disponível em http://www.nilc.icmc.usp.br/nilc/index.php/projetos_Acesso em: 5 de dezembro de 2015.

${ }^{3}$ Portal da Fundação UNDL, Disponível em http://www.undl.org _Acesso em: 30 de abril de 2015

${ }^{4}$ Portal Systran (http://www.systransoft.com), Eurotra (http://www.ccl.kuleuven.ac.be/about /EUROTRA.html), Acesso em 30 de abril de 2015
}

RECEBIDO EM: 04 de maio de 2015 ACEITO EM: 21 de maio de 2015 